\title{
SCIDiC
}

\author{
International Journal of Dentistry and Oral Science (IJDOS) \\ ISSN: 2377-8075
}

\section{Evaluation of Association Between Dental Occlusion and Temporomandibular Joint Disorders}

Research Article

Geethika. B ${ }^{1}$, M. P. Santhosh Kumar ${ }^{2 *}$, Manjari Chaudhary ${ }^{3}$

${ }^{1}$ Saveetha Dental College and Hospitals, Saveetha Institute Of Medical and Technical Science, Saveetha University, Chennai, India.

${ }^{2}$ Reader, Department of Oral and Maxillofacial Surgery, Saveetha Dental College, Saveetha Institute Of Medical and Technical Science, Saveetha University, Chennai, India.

${ }^{3}$ Senior Lecturer, Department of Oral Medicine and Radiology, Saveetha Dental College and Hospitals, Saveetha institute of medical and technical sciences, Saveetha University, Chennai, India.

\section{Abstract}

Temporomandibular disorders (TMD) are a class of degenerative muscular conditions associated with morphological and functional deformities. The aim of this study was to evaluate the association between dental occlusion and the occurrence of TMD among the patients visiting a private dental college. Among 86000 dental patients reported to our institution from June 2019 to March 2020, about 110 cases were included in the study by a simple random sampling method.These included 55 patients with temporomandibular disorder, and 55 patients without temporomandibular disorder. Any completely edentulous patients were excluded from the study. Each patient's dental records, treatment reports and photographs were reviewed thoroughly. Dental occlusion was evaluated and classified into class I malocclusion, class II div 1 malocclusion, class II div II malocclusion, and class III malocclusion. Demographic details like age, gender was also recorded.The collected data was validated, tabulated and analysed with Statistical Package for Social Sciences for Windows, version 23.0 (SPSS Inc., Chicago, IL, USA) and results were obtained. P value $<0.05$ was considered statistically significant.

Most (74.55\%) of the population exhibited Class 1 malocclusion, followed by $20 \%$ of the patients exhibiting Class 2 div 1 malocclusion and occlusion showing least incidence was Class 2 div 2 malocclusion which was present in $5.45 \%$ of the population. Among the patients with TMD, class 1 malocclusion was the most predominant type (51 patients) and the results were statistically significant. (p-value $<0.001$ ) Within the limits of the study, there is an association between dental occlusion and temporomandibular disorders. TMD is predominantly present in patients with class I malocclusion.

Keywords: Dental Occlusion; Malocclusion; Pain; TMD.

\section{Introduction}

Temporomandibular disorder (TMD) is considered as a repetitive motion disorder of the masticatory structures. It has many similarities to the other musculoskeletal disorders of the body [1, 2]. It is a musculoskeletal disorder within the masticatory system and the etiology can be multifactorial [3, 4]. These disorders are a class of degenerative musculoskeletal conditions associated with morphological and functional deformities [5-7].

About $33 \%$ of the individuals are affected by temporomandibular disorders (TMD) in their lifetime [2]. Similar to the other muscu- loskeletal disorders, the primary reason for which patients seek treatment include pain during function and at rest, and reduction in pain is generally the primary goal of therapy [8-11].

Patients also seek TMD therapy for TMJ locking, masticatory stiffness, limited mandibular range of motion, TMJ dislocation, and unexplained change in their occlusion [4, 12-14]. TMD can be managed by oneself by encouraging patients to rest their masticatory muscles by limiting voluntary movements and minimising the use of the muscle. Several studies have evaluated the role of dental occlusion in causing TMD in a varied population $[1,8,15$, 16]. The aim of the present study was to evaluate the association

*Corresponding Author:

Dr. M P Santhosh Kumar M.D.S,

Reader, Department of Oral and Maxillofacial Surgery, Saveetha Dental College, Saveetha Institute Of Medical and Technical Science, Saveetha University, Chennai, India. Tel: 9994892022

E-mail: santhoshsurgeon@gmail.com

Received: May 28, 2021

Accepted: June 17, 202

Published: June 24, 2021

Citation: Geethika. B, M. P. Santhosh Kumar, Manjari Chaudhary. Evaluation of Association Between Dental Occlusion and Temporomandibular Joint Disorders. Int J Dentistry Oral Sci. 2021;8(6):2799-2803. doi: http://dx.doi.org/10.19070/2377-8075-21000547

Copyright: M P Santhosh Kumar 2021. This is an open-access article distributed under the terms of the Creative Commons Attribution License, which permits unrestricted use, distribution and reproduction in any medium, provided the original author and source are credited. 
between TMD and dental occlusion in our regional population.

\section{Materials And Methods}

\section{Study design and Study setting}

This retrospective cross-sectional study was conducted in Saveetha dental college and hospital, Saveetha university, Chennai, to evaluate the association between dental occlusion and temporomandibular joint disorders among dental patients reporting to outpatient department of oral and maxillofacial surgery from June 2019 to March 2020. The study was initiated after approval from the institutional review board with the ethical approval number being: SDC/SIHEC/2020/DIASDATA/0619-0320.

\section{Study population and sampling}

Among 86000 dental patients reported to our institution from June 2019 to March 2020, about 110 cases were included in the study by a simple random sampling method to minimize sampling bias. These included 55 patients with temporomandibular disorder, and 55 patients without temporomandibular disorder. All missing or incomplete data, any completely edentulous patients were excluded from the study. Each patient's dental records, treatment reports and photographs were reviewed thoroughly. Cross verification of data for errors was done with the help of an external examiner.

\section{Data collection}

A single calibrated examiner evaluated the digital case records of the patients collected from June 2019 to March 2020 who reported with and without TMJ disorders and reviewed the status of their dental occlusion. Dental occlusion was evaluated and clas- sified into class I malocclusion, class II div 1 malocclusion, class II div II malocclusion, and class III malocclusion. Demographic details like age, gender was also recorded.

\section{Statistical Analysis}

The collected data was validated, tabulated and analysed with Statistical Package for Social Sciences for Windows, version 23.0 (SPSS Inc., Chicago, IL, USA) and results were obtained. Categorical variables were expressed in frequency and percentage; and continuous variables in mean and standard deviation. Chi-square test was used to test associations between categorical variables. $\mathrm{P}$ value $<0.05$ was considered statistically significant.

\section{Results And Discussion}

In our study, among 110 patients, there were an equal number of patients with TMDs $(n=55)$ and without TMDs $(n=55)$. Our study population consisted of 70 females $(63.64 \%)$ and 40 males $(36.36 \%)$ with a predominance of female gender. [Figure 1]. Age wise distribution of our study population showed more prevalence of younger population (10-19 year old patients - 35.45\%), followed by $30-39$ year old patients (27.27\%), 20-29 year (19.09\%), 40-49 year (11.82\%), and 50-59 (6.36\%) year old patients. [Figure 2].

Most (74.55\%) of the population exhibited Class 1 malocclusion, followed by $20 \%$ of the patients exhibiting Class 2 div 1 malocclusion and occlusion showing least incidence was Class 2 div 2 malocclusion which was present in $5.45 \%$ of the population. [Figure 3]. Among the patients with TMD, class 1 malocclusion was the most predominant type (51 patients) and the results were statistically significant. (Pearson chi-square value-19.243; DF-2, p-value $<0.001)$ [Figure 4][Table 1].

Figure 1. Bar chart showing gender wise distribution of our study population with predominance of female gender. $\mathrm{X}$ axis represents the gender and $\mathrm{Y}$ axis represents the percentage of patients in our study.

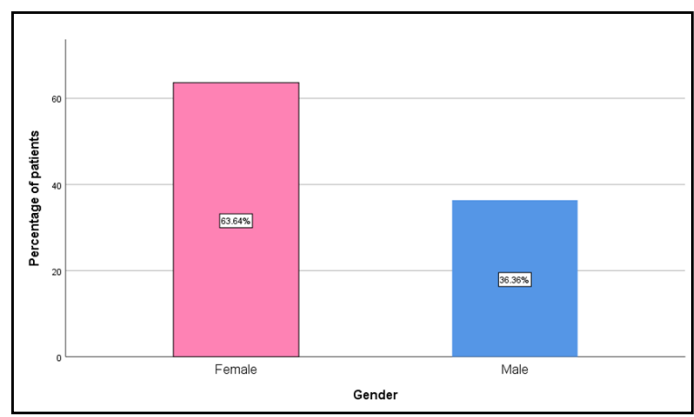

Figure 2. Bar chart showing age wise distribution of our study population. $\mathrm{X}$ axis represents the age category and $\mathrm{y}$ axis represents the percentage of patients in our study. It is seen most of the patients in our study belong to 10-19 years followed by 30-39 years.

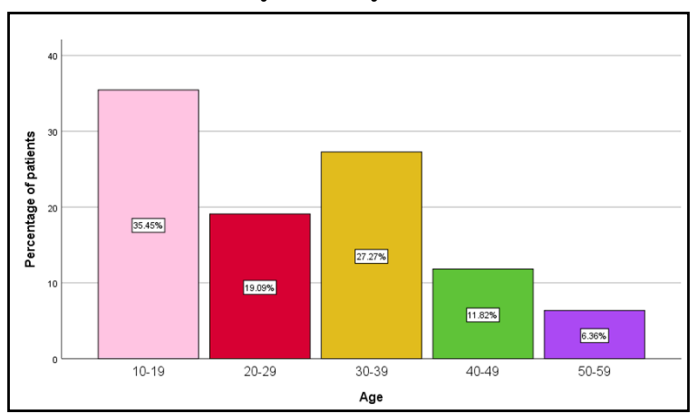


Figure 3. Bar chart showing distribution of dental occlusion in our study population. $X$ axis represents the type of occlusion and the $y$ axis represents the percentage of patients in our study. Class 1 malocclusion was the most predominant occlusion present among the study population.

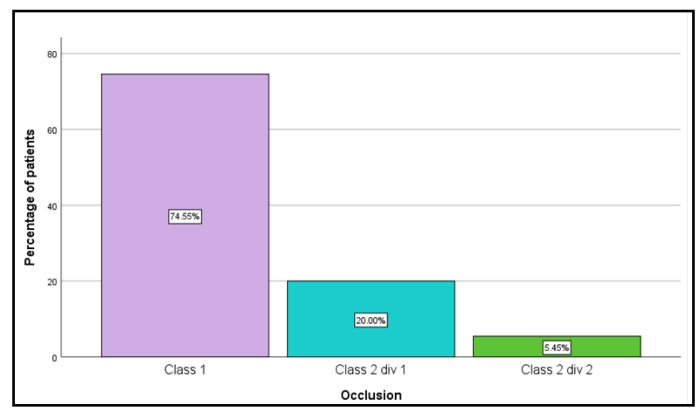

Figure 4. Bar chart shows the association between temporomandibular joint disorders and the type of occlusion. $\mathrm{X}$ axis represents the presence or absence of TMD and the $y$ axis represents the number of patients with different types of malocclusion. Chi- square analysis was done and the association was found to be statistically significant. Pearson chi-square value-19.243; DF-2, p-value $<0.001$. This shows that the patients with class 1 malocclusion are the most associated with TMD, this association is statistically significant.

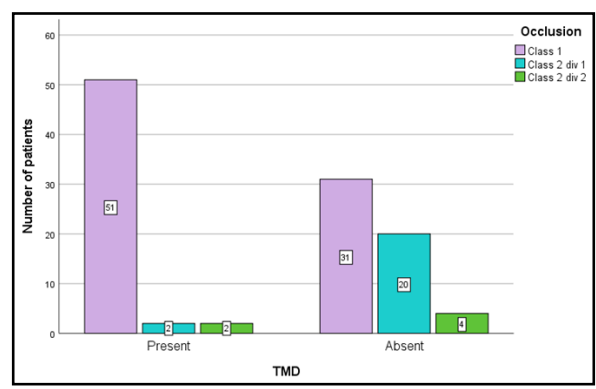

Table 1. Table shows the association between temporomandibular joint disorders and the type of malocclusion. Among the patients with TMD, class 1 malocclusion is the most predominant type(51 patients) and the results are statistically significant. (Pearson chi-square value-19.243; DF-2, p-value $<0.001$ ).

\begin{tabular}{|c|c|c|c|c|c|}
\hline \multirow{2}{*}{$\begin{array}{c}\text { Type of maloc- } \\
\text { clusion }\end{array}$} & $\begin{array}{c}\text { Temporomandibular } \\
\text { disorder }\end{array}$ & \multicolumn{3}{|c|}{ Statistical Analysis } \\
\cline { 2 - 3 } & Present & Absent & Pearson chi- square value & df & P-value \\
\hline Class 1 & 51 & 31 & & & \\
\hline Class 2 div 1 & 3 & 20 & & 2 & 0.001 \\
\hline Class 2 div 2 & 1 & 4 & & & \\
\hline Total & 55 & 55 & & & \\
\hline
\end{tabular}

In our study temporomandibular disorders were more common in females. Similar observations were made by Bonjardim et al [17], Widmalm et al [18] Sonmez et al [19].Our study shows that TMD is more prevalent in the younger population which is similar to the results of Bertoli et al [20]. But most studies proved that TMD is more prevalent in the older population [4, 21-24]. The reason for this difference could be due to the sample size of the studies and variations in the socioeconomic status and geographic location of the study population.

From our study we infer that TMD showed a statistically significant association with patients who had class 1 malocclusion $(81.5 \%)$ which is in agreement with the results of Kahn et al [25] and Bonjardim et al [17]. A study by Dzingute et al [26] concludes that the changes of occlusal parameters in the centric occlusion are observed among the patients with temporomandibular joint disorders. It is not only the occlusal and articulatory surfaces that play an important role in the human articulatory system, but also masticatory muscles which regulate the movements of the mandi- ble and determine the position of the condyle and the articulatory structures during exercise and at rest. Thus, occlusion remains as only one of the predisposing factors in the aetiology of TMDs.

A complete review of the existing literature shows that there are at least five major etiologic factors that can be associated with TMD, which include: dental occlusion, trauma, emotional stress, deep pain input, and parafunctional habits [27, 28]. The condyle resting in the articular fossa with the articular disc interposed contributes to the temporomandibular joint. The articular disc is mainly composed of dense fibrous connective tissues and it does not contain nerves and blood vessels [29]. This arrangement allows it to withstand heavy forces without damaging or creating a painful stimulus. The primary purpose of the disc is to separate, protect, and stabilize the condyle in the mandibular fossa during functional movements. The positional stability of the joint is however not determined by the articular disc. Just like any other joint, positional stability is determined by the muscles that embrace the joint and helps prevent the separation of the articular surfaces. The optimum orthopedically stable joint position is de- 
termined by the directional forces of these muscles. The major muscles that stabilize the TMJ are the elevators, which include: the temporalis, masseter, and medial pterygoid muscles. This is a basic orthopedic principle that is common to all mobile joints [30].

Temporomandibular disorders are classified into intra-articular (within the joint) or extra-articular (involving the surrounding musculature). The most common cause of TMD are musculoskeletal conditions, which account for at least $50 \%$ of the cases. The most common intra-articular cause of TMD is the articular disk displacement involving the condyle-disk relationship [8].

TMD in patients who present with pain in the TMJ area, the diagnosis by the clinician must be done in a vigilant manner to rule out the other conditions. Conditions that sometimes mimic TMD include dental caries or abscess, conditions resulting from muscle overuse (e.g., clenching, bruxism, excessive chewing, spasm), oral lesions (e.g., oral ulcerations, herpes zoster, herpes simplex, lichen planus), salivary gland disorders, maxillary sinusitis, trauma or dislocation, trigeminal neuralgia, glossopharyngeal neuralgia, postherpetic neuralgia, giant cell arteritis, primary headache syndrome, and cancer associated pain $[31,32]$.

There are quite a number of theories on the various treatments available for TMD. None of these theories are perfect, but the one that appears to be the most satisfactory is the one that targets the various complaints of the patients and their contributing factors. This treatment strategy correlates the treatment with patients' daily variations in symptoms $[33,34]$. For example, some TMD patients wake up with TMD pain that only lasts minutes to hours, which suggests that the nocturnal factors are the primary contributors to these symptoms that they develop [27, 35-38]. The other patients who presented with TMD symptoms developed it later in the day, which suggests that factors during the day are the primary contributors to these symptoms (e.g., daytime muscle tensing or clenching habits). Another group of patients presented with TMD symptoms that starts when they wake up and never goes away, which suggests that both nocturnal and daytime factors contribute to their symptoms [1, 33, 34, 36].

It is recommended that a patient with TMD should be treated with the least invasive procedures first. If this adequately resolves the pain, no other form of treatment is required. Patients are recommended to wear appropriate occlusal appliances at night as long as it benefits them [1, 8]. Surgery is rarely indicated for TMD patients. A study by Brown and Gaudet, 2002, [39] recorded over 2,000 TMD patients from many practices and found that only $2.5 \%$ of the patients underwent TMJ surgery (1.4\% arthrocentesis, $1.0 \%$ arthroscopy, and $0.1 \%$ open joint procedures). The obvious reasons for TMJ surgery include, infection, fracture, or neoplastic growth. The three primary TMD disorders for which patients are referred to a surgeon, are: 1) TMJ inflammation, 2) acute TMJ disc displacement without reduction (closed lock), and 3) TMJ ankylosis (painless severe limited opening)[1].

The limitations for the study include limited sample size from a particular geographical isolation. Future scope includes extensive research with multi-center studies including a larger sample size.

\section{Conclusion}

Within the limits of the study, there is an association between dental occlusion and temporomandibular disorders. TMD is predominantly present in patients with class I malocclusion.

\section{References}

[1]. Wright EF, North SL. Management and treatment of temporomandibular disorders: a clinical perspective. J Man ManipTher. 2009 Dec 1;17(4):24754.

[2]. Jesudasan JS, Wahab PU, Sekhar MR. Effectiveness of $0.2 \%$ chlorhexidine gel and a eugenol-based paste on postoperative alveolar osteitis in patients having third molars extracted: a randomised controlled clinical trial. $\mathrm{Br}$ J Oral Maxillofac Surg. 2015 Nov;53(9):826-30.Pubmed PMID: 26188932.

[3]. Kumar S, Rahman RE. Knowledge, awareness, and practices regarding biomedical waste management among undergraduate dental students. Asian J. Pharm. Clin. Res. 2017;10(8):341.

[4]. Sneha S. Knowledge and awareness regarding antibiotic prophylaxis for infective endocarditis among undergraduate dental students. Asian J. Pharm. Clin. Res. 2016 Oct 1:154-9.

[5]. Zarb GA, Carlsson GE. Temporomandibular disorders: osteoarthritis. J Orofac Pain. 1999 Oct 1;13(4):295-306.

[6]. Laskin DM. Temporomandibular disorders: the past, present, and future. Odontology. 2007 Jul;95(1):10-5.

[7]. Christabel A, Anantanarayanan P, Subash P, Soh CL, Ramanathan M, Muthusekhar MR, et al. Comparison of pterygomaxillary dysjunction with tuberosity separation in isolated Le Fort I osteotomies: a prospective, multi-centre, triple-blind, randomized controlled trial. Int J Oral Maxillofac Surg. 2016 Feb;45(2):180-5.Pubmed PMID: 26338075.

[8]. De Leeuw R, Klasser GD, editors. Orofacial pain: guidelines for assessment, diagnosis, and management. Chicago: Quintessence; 2008:316.

[9]. MP SK. Relationship between dental anxiety and pain experience during dental extractions. Asian J. Pharm. Clin. Res. 2017 Mar 1:458-61.

[10]. Patil SB, Durairaj D, Suresh Kumar G, Karthikeyan D, Pradeep D. Comparison of Extended Nasolabial Flap Versus Buccal Fat Pad Graft in the Surgical Management of Oral Submucous Fibrosis: A Prospective Pilot Study. J Maxillofac Oral Surg. 2017 Sep;16(3):312-321.Pubmed PMID: 28717289.

[11]. Rao TD, Kumar MS. Analgesic efficacy of paracetamol vs ketorolac after dental extractions. Res J Pharm Technol . 2018 Aug 1;11(8):3375-9.

[12]. Ribeiro RF, Tallents RH, Katzberg RW, Murphy WC, Moss ME, Magalhaes AC, et al. The prevalence of disc displacement in symptomatic and asymptomatic volunteers aged 6 to 25 years. J Orofac Pain. 1997 Winter;11(1):37-47. PMID: 10332309.

[13]. Abhinav RP, Selvarasu K, Maheswari GU, Taltia AA. The patterns and etiology of maxillofacial trauma in South India. Ann Maxillofac Surg. 2019 Jan;9(1):114-7.

[14]. Kumar $S$. The emerging role of botulinum toxin in the treatment of orofacial disorders: Literature update. Asian J. Pharm. Clin. Res. 2017;10(9):21-9.

[15]. Marimuthu M, Andiappan M, Wahab A, Muthusekhar MR, Balakrishnan A, Shanmugam S. Canonical Wnt pathway gene expression and their clinical correlation in oral squamous cell carcinoma. Indian J Dent Res. 2018 May $1 ; 29(3): 291-7$.

[16]. Packiri S, Gurunathan D, Selvarasu K. Management of paediatric oral ranula: a systematic review. J Clin Diagn Res. 2017 Sep;11(9):ZE06-9.

[17]. Bonjardim LR, Lopes-Filho RJ, Amado G, Albuquerque RL, Goncalves SR Association between symptoms of temporomandibular disorders and gender, morphological occlusion, and psychological factors in a group of university students. Indian J Dent Res. 2009 Apr-Jun;20(2):190-4.Pubmed PMID: 19553721.

[18]. Widmalm SE, Westesson PL, Kim IK, Pereira FJ, Lundh H, Tasaki MM. Temporomandibular joint pathosis related to sex, age, and dentition in autopsy material. Oral Surg Oral Med Oral Pathol. 1994 Oct;78(4):416-25. Pubmed PMID: 7800370.

[19]. Sönmez H, Sari S, Oksak Oray G, Camdeviren H. Prevalence of temporomandibular dysfunction in Turkish children with mixed and permanent dentition. J Oral Rehabil. 2001 Mar;28(3):280-5.Pubmed PMID: 11394375.

[20]. Bertoli FM, Bruzamolin CD, Pizzatto E, Losso EM, Brancher JA, de Souza JF. Prevalence of diagnosed temporomandibular disorders: A cross-sectional study in Brazilian adolescents. PloS one. 2018 Feb 8;13(2):e0192254.

[21]. Rahman R. Knowledge, Attitude And Awareness Of Dental Undergraduate Students Regarding Hiv/Aids Patients. Asian J. Pharm. Clin. Res. 2017 May $1: 175-80$.

[22]. Patturaja K, Pradeep D. Awareness of Basic Dental Procedure among General Population. Res J Pharm Technol. 2016 Sep 1;9(9):1349.

[23]. Vijayakumar Jain S, Muthusekhar MR, Baig MF, Senthilnathan P, Loganathan S, Abdul Wahab PU, et al. Evaluation of Three-Dimensional Changes in Pharyngeal Airway Following Isolated Lefort One Osteotomy for the Correction of Vertical Maxillary Excess: A Prospective Study. J Maxillofac Oral 
Surg. 2019 Mar;18(1):139-146.Pubmed PMID: 30728705.

[24]. Muthukrishnan A, Sekar GS. Prevalence of temporomandibular disorders in Chennai population. J Indian Acad Oral Med Radiol. 2015 Oct 1;27(4):508.

[25]. Kahn J, Tallents RH, Katzberg RW, Ross ME, Murphy WC. Prevalence of dental occlusal variables and intraarticular temporomandibular disorders: molar relationship, lateral guidance, and nonworking side contacts. J Prosthet Dent. 1999 Oct;82(4):410-5.Pubmed PMID: 10512959.

[26]. Dzingute A, Pileičikienè G, Baltrušaityte A, Skirbutis G. Evaluation of the relationship between the occlusion parameters and symptoms of the temporomandibular joint disorder. Acta Med Litu. 2017;24(3):167-75.

[27]. Okeson JP. Management of Temporomandibular Disorders and Occlusion. 1998. 638.

[28]. Sweta VR, Abhinav RP, Ramesh A. Role of Virtual Reality in Pain Perception of Patients Following the Administration of Local Anesthesia. Ann Maxillofac Surg. 2019 Jan-Jun;9(1):110-113.Pubmed PMID: 31293937.

[29]. Wink CS, Onge MS, Zimny ML. Neural elements in the human temporomandibular articular disc. J Oral Maxillofac Surg. 1992 Apr 1;50(4):334-7.

[30]. Bennett KA. Oral anatomy. Fifth Edition. By Harry Sicher and E. Lloyd DuBrul. 502 pp. and 319 ill. C. V. Mosby Co., St. Louis. 1970. $\$ 17.50$. Am. J. Phys. Anthropol. 1972;36:144-5. Available from: http://dx.doi. org/10.1002/ajpa.1330360118

[31]. Okeson JP, de Leeuw R. Differential diagnosis of temporomandibular disorders and other orofacial pain disorders. Dent. Clin. 2011 Jan 1;55(1):10520.
[32]. Zakrzewska JM. Differential diagnosis of facial pain and guidelines for management. Br J Anaesth. 2013 Jul 1;111(1):95-104.

[33]. Orlando B, Manfredini D, Salvetti G, Bosco M. Evaluation of the effectiveness of biobehavioral therapy in the treatment of temporomandibular disorders: a literature review. Behav Med. 2007 Fall;33(3):101-18.Pubmed PMID: 18055333.

[34]. Chen CY, Palla S, Erni S, Sieber M, Gallo LM. Nonfunctional tooth contact in healthy controls and patients with myogenous facial pain. J Orofac Pain. 2007 Summer;21(3):185-93.Pubmed PMID: 17717957.

[35]. Cadden SW. Orofacial pain. Guidelines for assessment, diagnosis, and management, 4th edition (2008). Eur J Orthod .2009;31:216-7. Available from: http://dx.doi.org/10.1093/ejo/cjp007

[36]. Murphy E. Managing orofacial pain in practice. Quintessence Publishing Company Ltd; 2019 Mar 19:160.

[37]. Rossetti LM, Rossetti PH, Conti PC, Araujo CD. Association between sleep bruxism and temporomandibular disorders: a polysomnographic pilot study. Cranio. 2008 Jan 1;26(1):16-24.

[38]. Camparis CM, Siqueira JT. Sleep bruxism: clinical aspects and characteristics in patients with and without chronic orofacial pain. Oral Surg Oral Med Oral Pathol Oral RadiolEndod. 2006 Feb 1;101(2):188-93.

[39]. Brown DT, Gaudet EL. Temporomandibular disorder treatment outcomes: second report of a large-scale prospective clinical study. Cranio. 2002 Oct;20(4):244-53.Pubmed PMID: 12403182. 